\title{
Cognitive Support Tools for a Pre- Performance Routine in a Darts Game
}

\author{
Hironori Hiraishi, Ashikaga University, Ashikaga, Japan \\ iD https://orcid.org/0000-0002-0447-9114
}

\begin{abstract}
This paper describes two types of a cognitive support tools for a pre-performance routine (PPR) in a darts game. PPRs entail the performance of determined motions before an action and are often executed in sports for the purpose of removing stress or raising concentration. The concentration-stabilizing phenomenon was discovered by the previous research, and it determined that the phenomenon appears more conspicuous in the case of experts and PPRs. A tool using a simple brainwaves sensor has been designed and shows us the current status of concentration and notifies us of the concentrationstabilizing phenomenon on a tablet computer. Another tool has been developed on a smart watch with a heart rate sensor. The smart watch indicated heartbeat as a "beep" sound to a user. It was designed based on a result that indicated that darts game scores tend to improve by throwing immediately after a heartbeat. The effectiveness of the tools were verified in several experiments.
\end{abstract}

\section{KEYWORDS}

Brainwaves, Cognitive Support Tool, Concentration-Stabilizing Phenomenon, Darts Game, Heart Rate Sensor, Heartbeat, Pre-Performance Routines, Smart Watch

\section{INTRODUCTION}

Pre-performance routines (PPRs) entails the performance of determined motions before an action and are often executed in sports for the purpose of removing stress or raising concentration. PPRs have been defined as physical and psychological preparation before performing tasks (Cotterill, 2010). In the area of sport science and psychology, their effectiveness has been experimentally reported in various sports, such as basketball free throws (Lonsdale \& Tam, 2008), water polo penalty shots (Marlow et al., 1998), serves in volleyball (Velentzas et al., 2011), golf (Cotterill et al., 2010), and football (Mesagno \& Mullane-Grant, 2010). Moreover, in the area of neuroscience and brain science, studies have analyzed the difference in the activating parts of the brain between experts and novices using functional magnetic resonance imaging through the computer simulation tasks of archery (Kim et al., 2008) and golf (Milton et al., 2007).

The analysis of results of PPRs using a simple brainwaves sensor were previously reported (Hiraishi, 2017). In that paper, concentration levels were measured while throwing given objects at specific targets, such as the free throw in basketball and darts games. First, the concentration levels 
in basketball free throws were analyzed and the differences between experts and novices recorded. Subsequently, the influence of PPRs in dart games was investigated. A concentration-stabilizing phenomenon was discovered before each throw and the phenomenon appears more conspicuously in experts and when PPRs were performed. This implies that a phenomenon similar to PPR exists in experts, and leads to the effects of stress removal or increased concentration, both of which are the purpose of PPRs, and is similar to the stabilizing of concentration which could be a result of modifications in brainwaves.

The heart rate during a PPR was also analyzed (Hiraishi, 2020). Heart rate data has been used as a parameter of health or mental workload in many fields. Heart rate variability (Delliaux et al., 2019) is a well-known biological phenomenon that reflects autonomic nerve activity. Low Frequency (LF), which reflects sympathetic nerve activity, and High Frequency (HF), which reflects parasympathetic nerve activity, are obtained through spectrum analysis. The LF/HF ratio, which represents their index, is used as a parameter for assessing the stress level (Pomeranz et al., 1985). There is an existing case study that shows the analysis of the relationship between heart rate and shot accuracy in basketball (Ardigò et al., 2018). Similar to previous studies (Hiraishi, 2017; Hiraishi, 2018), in that study (Hiraishi, 2020), a PPR in a darts game was focused upon, heart rate changes during the PPR was analyzed, and the timing of heartbeat and throwing was investigated. The result showed that darts game scores tend to improve by throwing immediately after a heartbeat.

PPRs are very attractive and well-known techniques in sports. However, the mechanisms by which PPRs accomplish their effects are not clear (Cotterill, 2010). PPRs are unique to individuals (Cotterill et al., 2010), and a general method for configuring PPRs does not exist. Therefore, they are designed by trial and error through consultation and discussion among specialists and players (Marlow et al., 2011). However, these analysis results of brainwaves and heart rate indicate that we can objectively determine the types of behavioral sequences that are appropriate for PPRs by determining concentration levels by monitoring of brainwaves or heartbeat. In addition, we show that once a PPR is known to be effective, it can be trained to achieve greater stabilization of concentration or throwing immediately after a heartbeat.

In this paper, two types of a cognitive support tool for PPRs in darts game have been introduced. A tool using a simple brainwaves sensor has been designed, and allows the determination of the baseline level of concentration, and the concentration-stabilizing phenomenon on a tablet computer. Another tool has been developed on a smart watch with a heart rate sensor. The smart watch indicated heartbeat as a "beep" sound to a user. The effectiveness of this tool was verified in several experiments.

This paper is organized as follows: Section 2 introduces the simple brainwaves sensor that we adopted. Section 3 describes the support tool using simple brainwaves sensor and shows the effectiveness of the tool. Section 4 presents the analyses for heart rate change and timing of heartbeat and throwing. Section 5 explains the support tool based on heartbeat and details the effectiveness of the tool. Section 6 concludes this paper.

\section{THE SIMPLE BRAINWAVES SENSOR}

We adopted the B3 Band shown in Figure 1, which is a simple electroencephalograph produced by B-Bridge International, Inc. The size is $54 \mathrm{~mm}(\mathrm{~L}) \times 25 \mathrm{~mm}(\mathrm{~W}) \times 17 \mathrm{~mm}(\mathrm{H})$, and the weight is approximately $100 \mathrm{~g}$. The band is small and may be comfortably worn during exercise. The right side of Figure 1 shows an example of a user wearing the B3 Band. There is an electrode on the left ear hook, and two other electrodes attached to the forehead of the band. Data recording brainwaves are measured through these electrodes and transmitted to tablets or PCs through bluetooth. Data may be monitored on a tablet in real time using the software provided with the band. Applications may also be developed using PC development kits.

Eight types of brainwaves (Delta, Theta, low Alpha, high Alpha, low Beta, high Beta, low Gamma, and high Gamma) are acquired, which comprise the commonly recognized types of brainwaves. These 
Figure 1. Simple brainwaves sensor B3 Band and wearing example

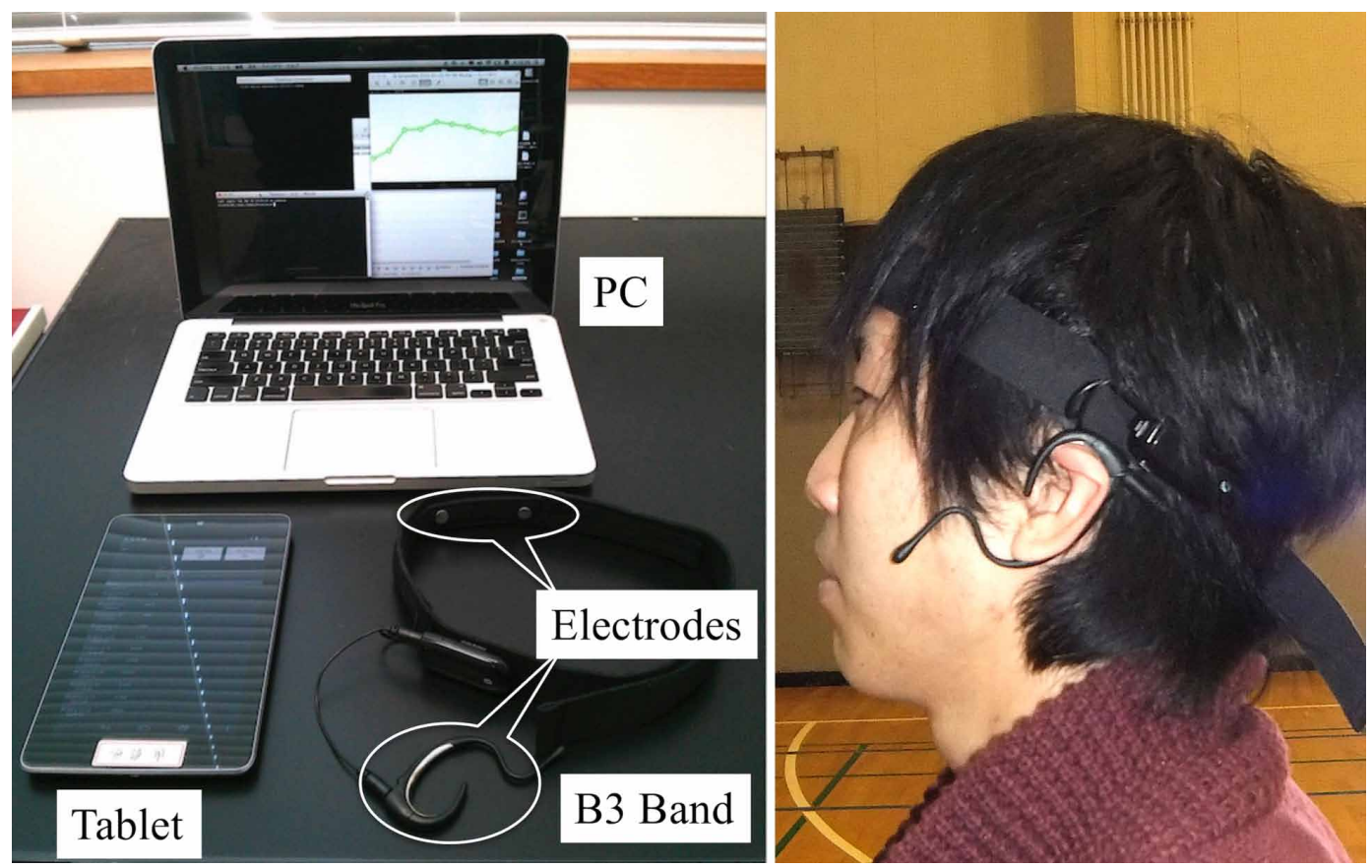

waves represent values that have no units, and are meaningful only when compared with each other, along with temporal fluctuations. The value for each wave is calculated in the B3 Band and recorded in computer every second.

The B3 Band adopts the brainwaves measurement module developed by NeuroSky, Inc., and records "attention" and "mediation" values using the proprietary algorithm eSence, which are considered the concentration and relaxation levels, respectively. These values range from 0 to 100 , with 100 being the highest level. The algorithm used for calculating values of the waves is proprietary. However, its accuracy has been verified by successfully mediating robotic control of concentration and relaxation levels (Hiraishi, 2015). This paper also uses the "attention" value as the concentration level, same as that in a previous study (Hiraishi, 2017).

\section{THE SUPPORT TOOL USING SIMPLE BRAINWAVES SENSOR}

The concentration-stabilizing phenomenon appears more conspicuously in the case of experts and in PPRs (Hiraishi 2017). Therefore, by checking the concentration level obtained from brainwaves, the type of behavior sequences that are appropriate for PPRs can be determined. Moreover, a training of a particular PPR is also available after establishing its efficacy. Notifications of stabilized concentration levels might be useful. However, disturbing concentration by notification should be avoided. From the experiments (Hiraishi 2018), the results had been obtained, which indicated that while concentration is disturbed by notification, it becomes difficult to concentrate without notification. Therefore, the best notification method is one where users can become aware of the stabilization states naturally without a specific change in notification.

Figure 2 shows the graphical user interface of the support tool using simple brainwaves sensor. The green graph on the left is scrolling from right to left and always shows the concentration level for 10 seconds. The number on the right is the standard deviation seen for a period of 3 seconds. The 


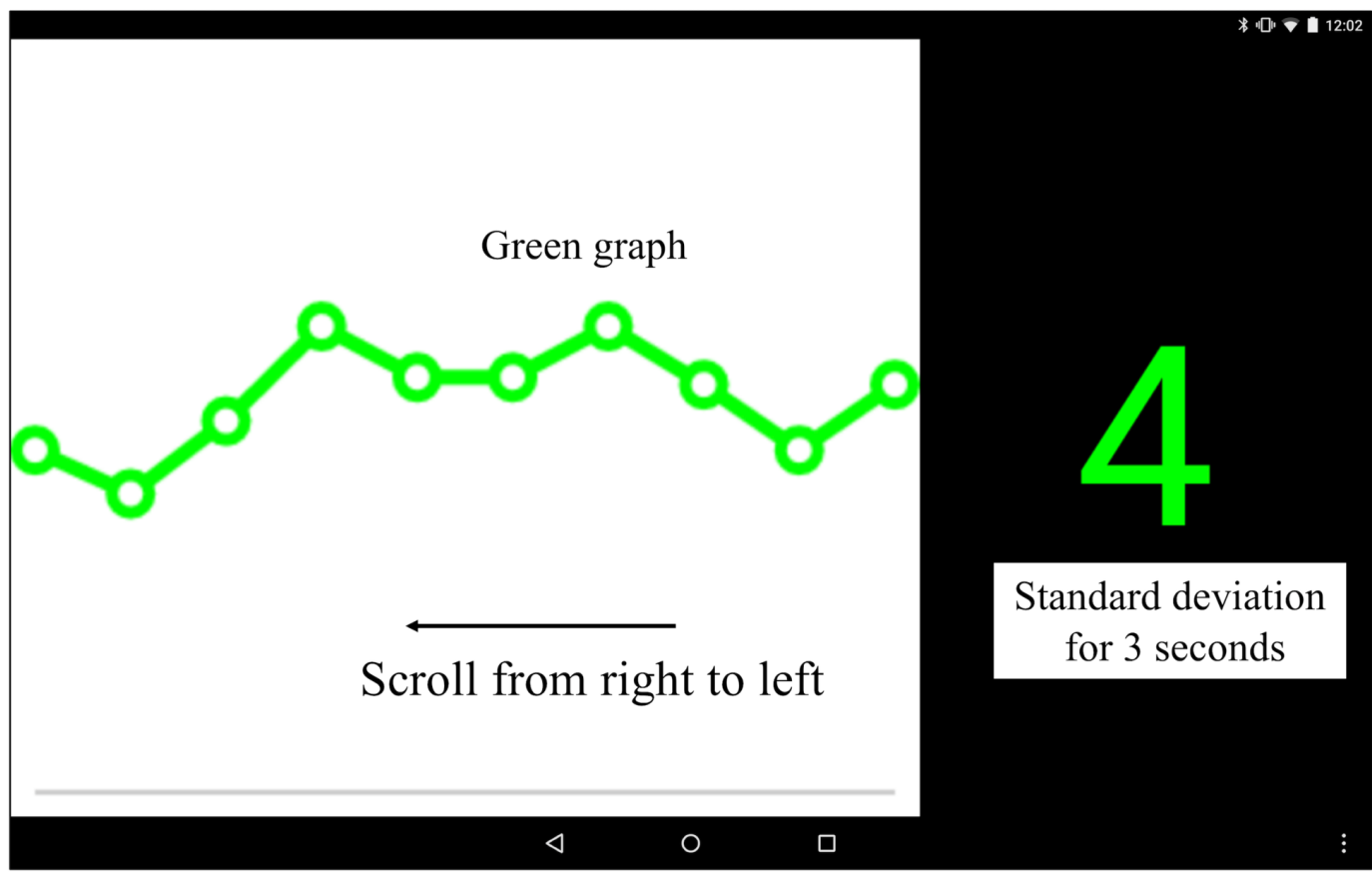

number continuously changes. Special notifications like color change and beep are not necessary in this interface. The user can recognize the stabilizing with effect by a numerical value of "zero."

Generally, PPRs are different in every case (Cotterill et al., 2010), and decided by trial and error based on the discussions between a player and a trainer (Marlow et al., 1998). Therefore, in this study, some routines were prepared in advance, and all subjects threw darts only after performing the routine. The PPR for each subject was determined from the score of the routine. The number of "take back before release" as a routine was similar to previous studies (Hiraishi, 2017). Figure 3 shows the steps for throwing a dart. A dart is released after "aiming" and "take back." The subjects were instructed to perform "aiming" and "take back" once, twice, and thrice before "release," in separate attempts of the PPRs. Any influence or trained behavior because of repetitiveness was avoided by conducting experiments, with a specific number of "take back," at intervals of approximately one week.

The effectiveness of the support tool was confirmed by testing performance. PPRs of two subjects (male students in their twenties) were decided as the number of takeback actions which yielded the highest score. Subsequently, they practiced their dart games with their PPRs twice a week for three months until their scores improved to some extent. Table 1 shows the best score of each subject. In a darts game, there are numbers on the dart board and whichever number is hit by the darts is added to the score in the game. To eliminate randomness The subjects were instructed to throw darts by aiming at the center of the dart board. The score depended on the distance $(\mathrm{cm})$ of the dart from the center. Therefore, a smaller value indicated a better score. Table 1 shows the average and standard deviation of the best day, each subject having different best days. However, they both recorded the best average and the best standard deviation in a same day. Subject A recorded the best score at the last day, and Subject B recorded the best score at the day after the last day.

Figure 4 shows the situation of the experiment. The tool was running on the tablet. At first, subjects executed only their PPRs without throwing as the training of PPRs themselves. They trained their PPRs as looking at the tablet and tried making the value of standard deviation less than three. 

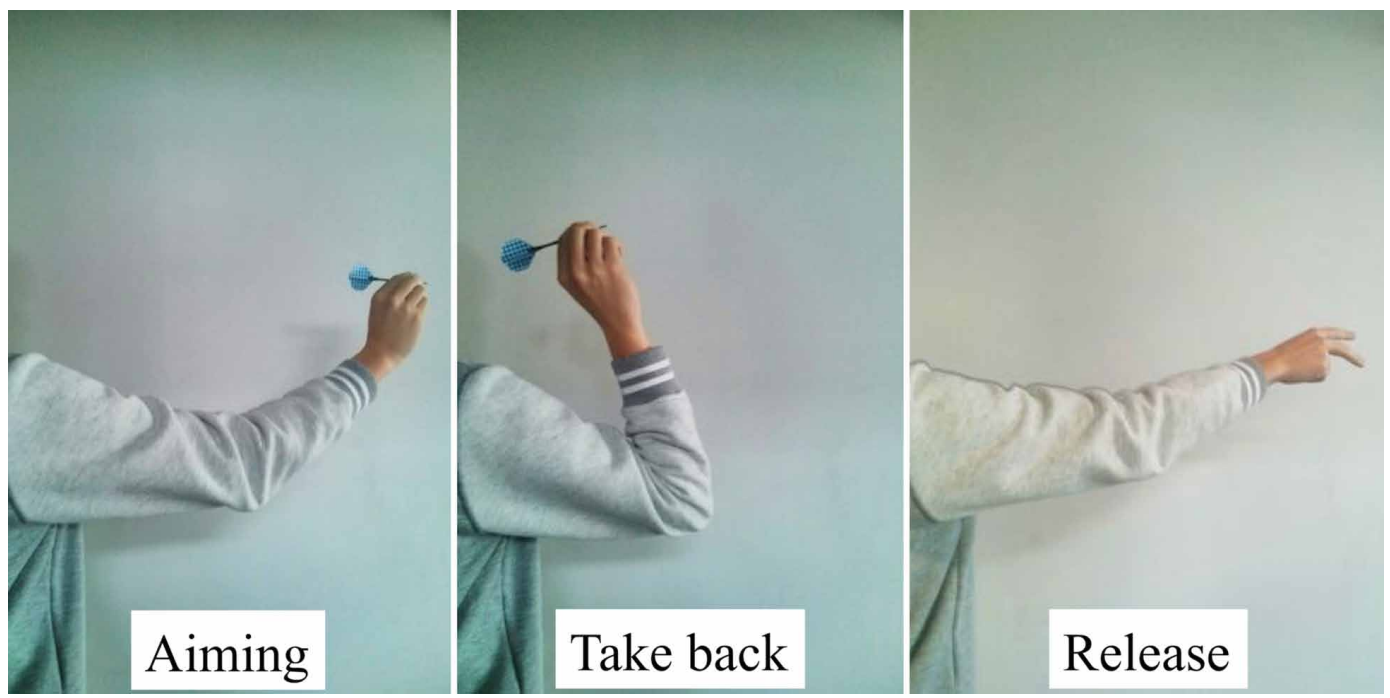

They continued the training until they could record the value of less than three, thrice in a row. After the training, subjects threw darts by two methods; one was throwing with looking at the tablet, and another was throwing without the tablet. Each subject threw darts 9 times by each method. The total became 18 throws.

Table 2 shows the scores after training. Compared with Table 1, average scores were improved when Subject A looked at the tablet, but an increase was seen in Subject B when he did not look at the tablet. Although there is an individual difference, it can be considered that this result indicated the effectiveness of the PPR training. In the case of Subject A, the standard deviations were improved in both methods. This indicates that Subject A learned to concentrate more by PPR training and could get good score constantly.

\section{ANALYSIS OF HEART RATE AND TIMIING OF HEARTBEAT AND THROWING}

An experiment was conducted with 3 subjects (male students in their twenties), who were different from subjects tested in the previous section, and the change in heart rate and timing of heartbeat and throwing were analyzed.

Figure 5 shows a heart rate sensor. The heart rate sensor WHS-1 is manufactured by Union Tool Co. in Japan. The electronodes of the sensor were attached to the subject's chest. The data from the sensors were sent through wireless communication to a personal computer. The data were stored and analyzed on the computer using a special analysis software to obtain the measurement time, heart rate, heartbeat interval, body temperature, and LF/HF ratio.

Table 1. The best score (unit: $\mathrm{cm}$ )

\begin{tabular}{|l|l|l|}
\hline & \multicolumn{1}{|c|}{ Subject A } & \multicolumn{1}{c|}{ Subject B } \\
\hline Average & 6.65 & 7.58 \\
\hline Standard Deviation & 3.49 & 3.45 \\
\hline
\end{tabular}




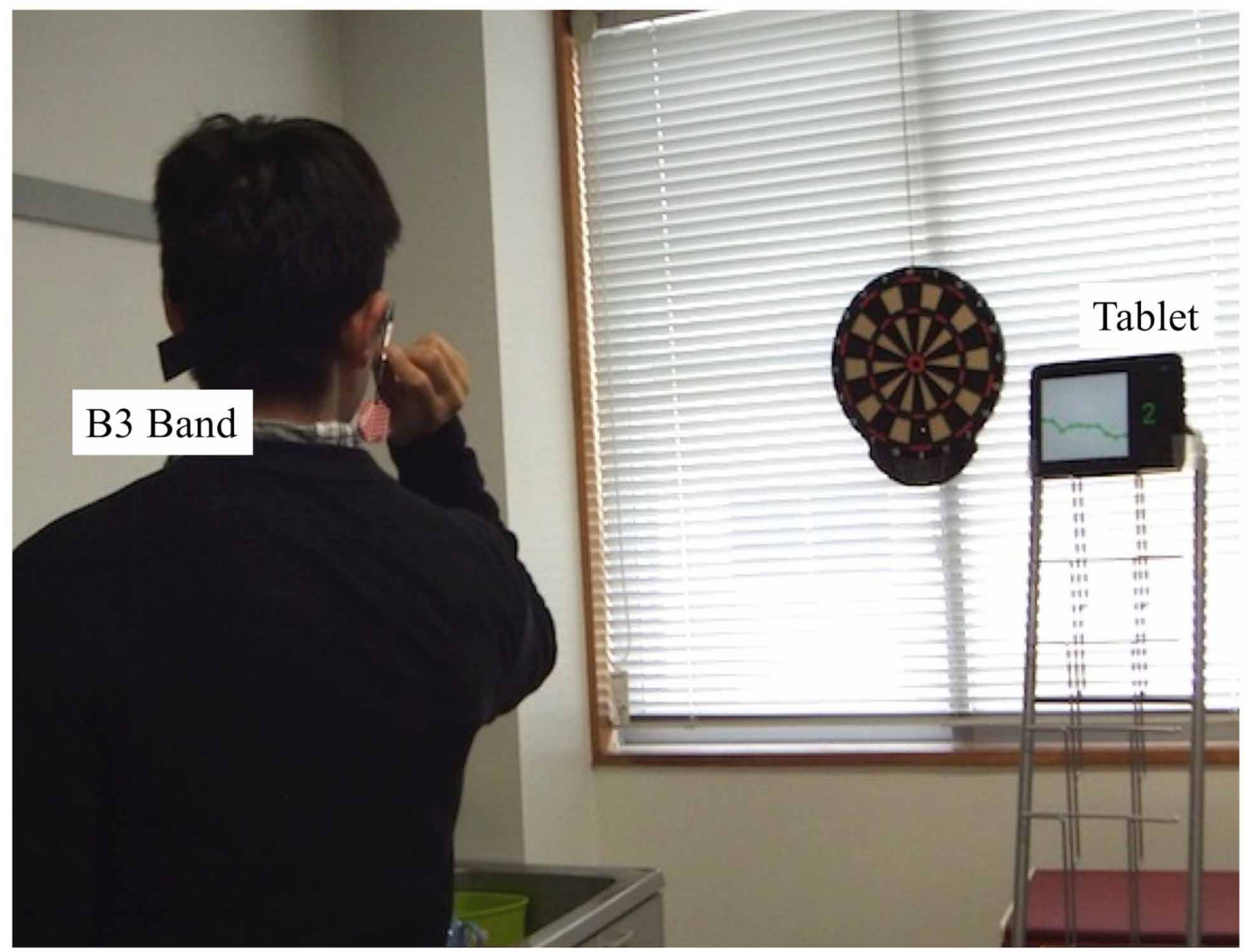

Figure 6 shows the setup for the experiment. All subjects were instructed to throw darts while wearing the heart rate sensor. We video-recorded the entire experiment as shown in Figure 5, which started from clicking the button for data collection using the computer application. The recording time was synchronized with the time of data collection, after which the heart rate during throwing was analyzed.

All the subjects threw darts 9 times with each of the specified number (once, twice and thrice) of "take back." Table 3 shows the average and standard deviation of scores of each subject. Subjects 1 and 2 had the lowest average score and standard deviation values in the "once take back." This indicated that Subjects 1 and 2 could throw darts stably at a point nearer to the center after taking the dart back once. Therefore, "once take back" was considered as a suitable PPR for Subjects 1 and

Table 2. Score after training (unit: $\mathrm{cm}$ )

\begin{tabular}{|l|l|l|l|}
\hline \multicolumn{1}{|c|}{ Method } & \multicolumn{1}{|c|}{ Value } & \multicolumn{1}{c|}{ Subject A } & \multicolumn{1}{c|}{ Subject B } \\
\hline \multirow{2}{*}{$\begin{array}{l}\text { With } \\
\text { Tablet }\end{array}$} & Average & $\mathbf{5 . 6 6}$ & 8.94 \\
\cline { 2 - 5 } & Standard Deviation & $\mathbf{2 . 7 8}$ & 5.98 \\
\hline \multirow{2}{*}{$\begin{array}{l}\text { Without } \\
\text { Tablet }\end{array}$} & Average & 8.33 & $\mathbf{6 . 9 4}$ \\
\cline { 2 - 5 } & $\begin{array}{l}\text { Standard } \\
\text { Deviation }\end{array}$ & $\mathbf{3 . 0 8}$ & 4.48 \\
\hline
\end{tabular}


Figure 5. Heart rate sensor

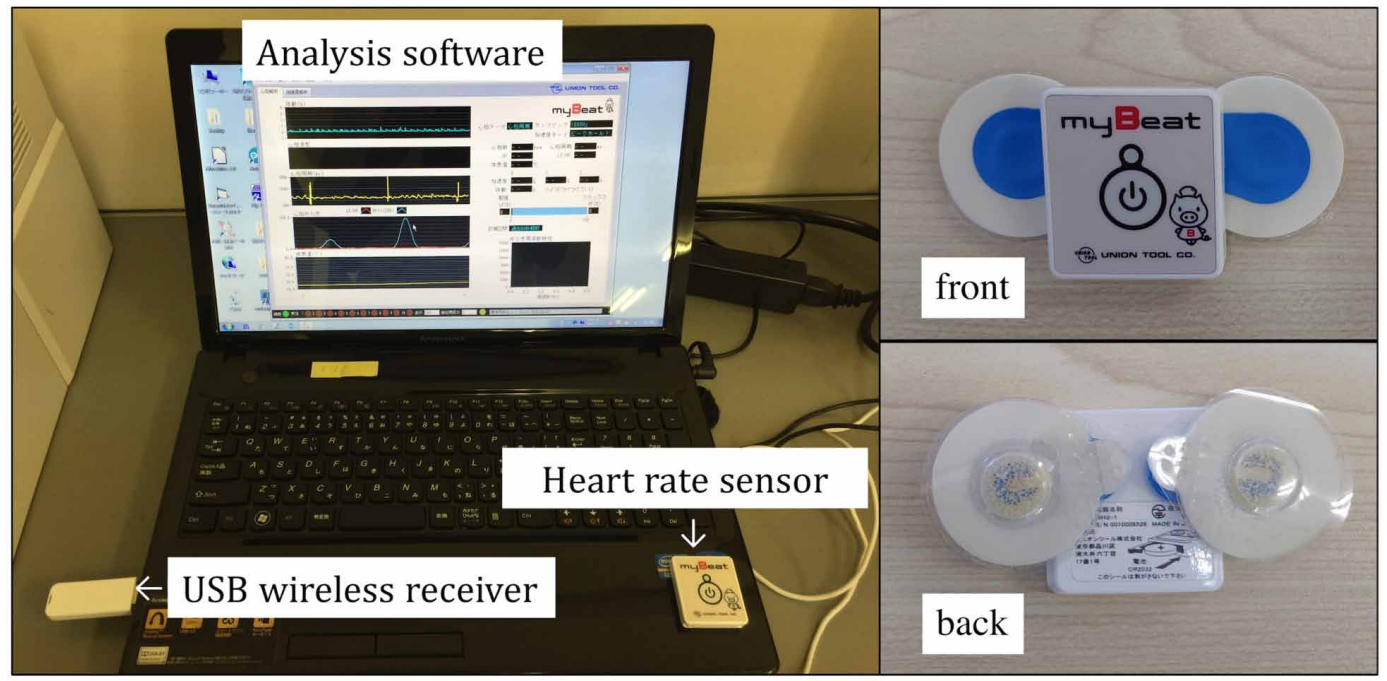

2. Subject 3 did not show smaller values for both the average score and standard deviation under any particular number of "take back." In "thrice take back", the average value was the highest, and standard deviation was the lowest for Subject 3. This indicated that Subject 3 consistently received poor score with "thrice take back." Therefore, "thrice take back" was regarded as the worst PPR for Subject 3.

Figure 6. Experimental setup

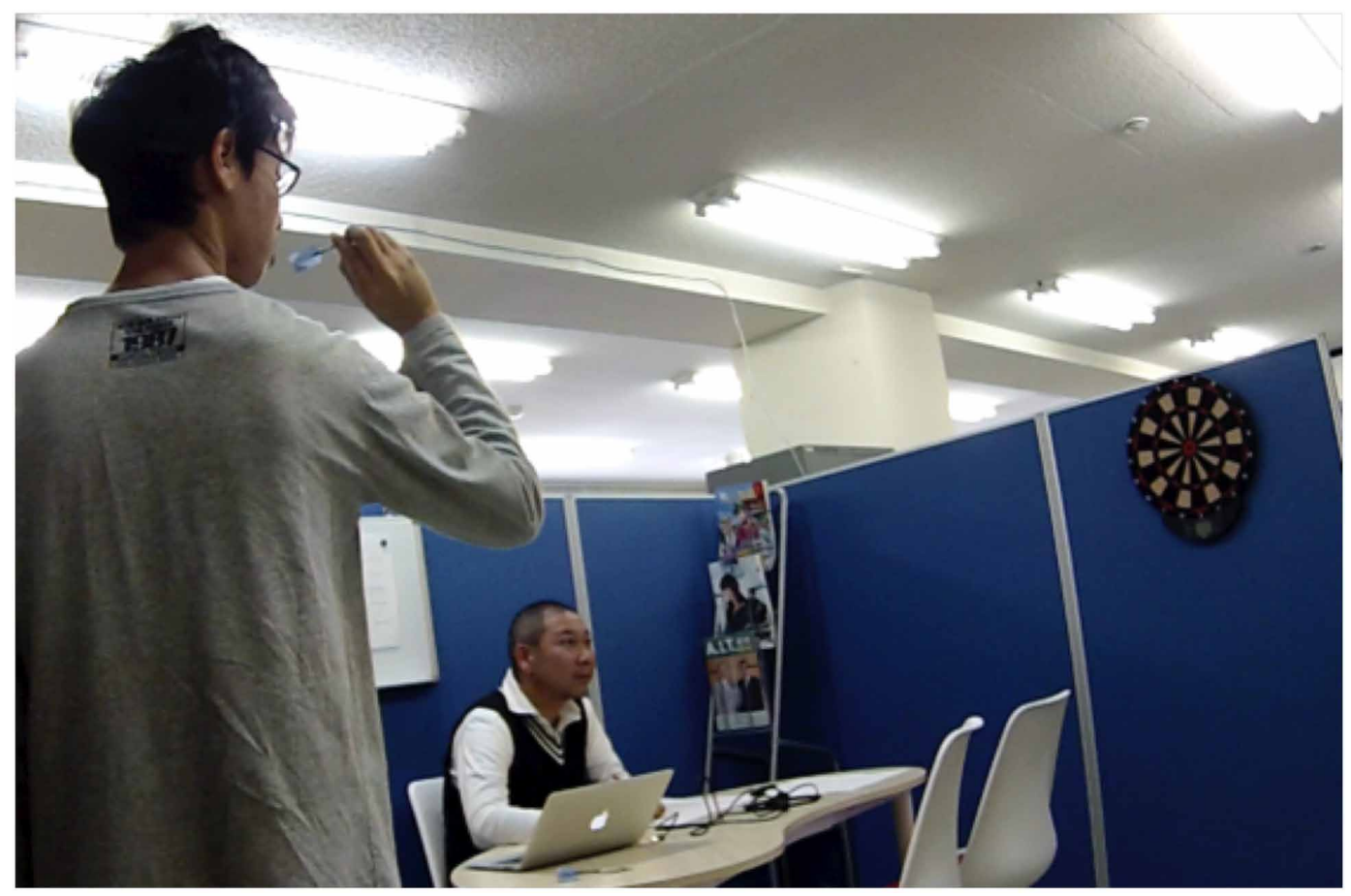


Table 3. Average score and standard deviation (unit: $\mathrm{cm}$ )

\begin{tabular}{|l|l|l|l|l|}
\hline \multicolumn{2}{|c|}{ Number of “take back” } & \multicolumn{1}{c|}{ Once } & \multicolumn{1}{c|}{ Twice } & \multicolumn{1}{c|}{ Thrice } \\
\hline \multirow{3}{*}{ Subject 1} & Average & 5.844 & 7.222 & 9.289 \\
\cline { 2 - 5 } & Standard deviation & 3.939 & 5.282 & 4.494 \\
\hline \multirow{3}{*}{ Subject 2 } & Average & 5.844 & 7.200 & 9.289 \\
\cline { 2 - 5 } & Standard deviation & 3.940 & 5.275 & 4.492 \\
\hline \multirow{3}{*}{ Subject 3 } & Average & 8.333 & 10.267 & 10.433 \\
\cline { 2 - 5 } & Standard deviation & 5.434 & 4.341 & 3.114 \\
\hline
\end{tabular}

To study the change in heart rate, an average heart rate for $3 \mathrm{~s}$ before throwing was compared with the same after throwing. Table 4 summarizes the heart rate change of each subject; "Rise" is the ratio of the increase in average heart rates before and after throw, and "Drop" is the ratio of the decrease in the average heart rate before and after throw. The values of "Rise" for Subjects 1 and 2 are the highest under "once take back". Compared with Table 1, "once" is regarded as a suitable PPR for Subjects 1 and 2, which indicates that heart rate tends to rise during PPR. The value of "Rise" under "twice take back" for Subject 3 is the highest. Based on this, the "twice take back" may be the most suitable PPR for Subject 3.

It is said that heart rate generally increases owing to intention and excitement and then reduces steadily because of concentration. Therefore, the increase in heart rate during PPR can be considered as the mental preparation to reach the concentration condition.

Next, the timing of heartbeat and throwing was analyzed. A heartbeat interval was separated equally into three sections, as shown in Figure 7; a section after heartbeat (After), a middle section (Middle), and a section before the next heartbeat (Before). Table 5 shows the percentage of timing of throwing darts by each subject during each section of the heartbeat interval. Based on the number of "take back" that was considered as a suitable PPR for each subject, the results for the "After" sections were the highest for all subjects. This result indicated that scores increased when each subject threw immediately after a heartbeat. It can be considered that PPRs led the throwing of darts after the heartbeat. The timing after a heartbeat is when fresh blood circulates through the body. It can be stated that throwing at that time leads to higher scores and better performance.

\section{THE SUPPORT TOOL BASED ON HEATBEAT AND IT'S EFFECTIVENESS}

The results described in the previous section showed that darts game scores tend to improve by throwing immediately after a heartbeat. If subjects can perceive their heartbeat timing, they can

Table 4. Change of heart rate (\%)

\begin{tabular}{|l|l|l|l|l|}
\hline \multicolumn{2}{|c|}{ Number of "take back" } & Once & \multicolumn{1}{c|}{ Twice } & \multicolumn{1}{c|}{ Thrice } \\
\hline \multirow{3}{*}{ Subject 1} & Rise & 78 & 44 & 67 \\
\cline { 2 - 6 } & Drop & 22 & 56 & 33 \\
\hline \multirow{3}{*}{ Subject 2 } & Rise & 56 & 22 & 33 \\
\cline { 2 - 6 } & Drop & 44 & 78 & 67 \\
\hline \multirow{3}{*}{ Subject 3 } & Rise & 33 & 78 & 56 \\
\cline { 2 - 6 } & Drop & 67 & 22 & 44 \\
\hline
\end{tabular}




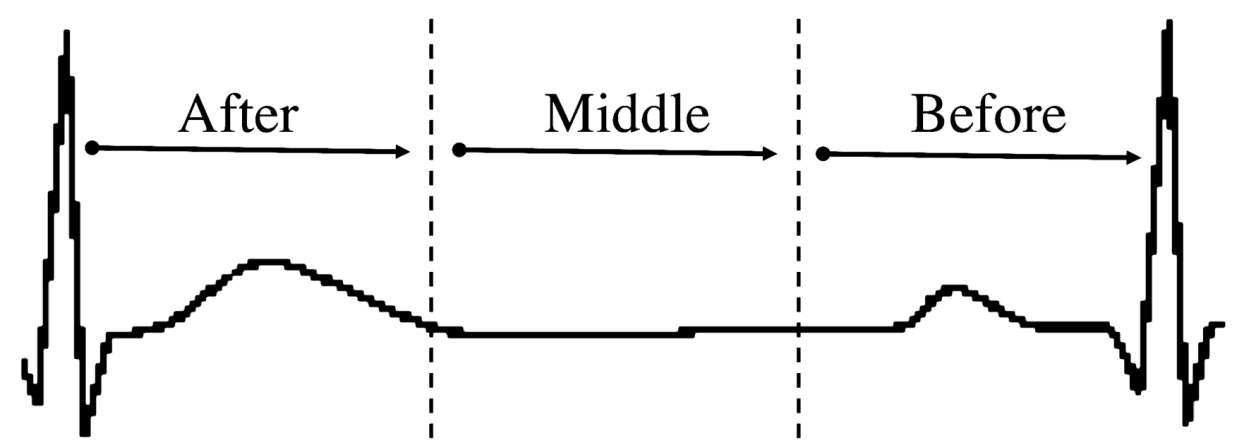

throw darts based on the timing of their heartbeat and obtain higher scores. Therefore, a system was developed to provide a user with a "beep" sound indicating a heartbeat using a smart watch with a heart rate sensor. Figure 8 shows the smart watch (Kingwear KW88), which has a heart rate sensor on the back. The Android OS (Version 5.1) was used for the smart watch and Android programming was used for the developed system. The subjects could listen to their heartbeat using the smart watch and throw darts immediately after the "beep" sound.

Two different set of experiments were conducted with 3 subjects (male students in their twenties); one with the smart watch and other without. These students were different from the subjects of the previous experiments. Each subject threw the dart 9 times with the same number of "take back" (once, twice, thrice) as in the previous experiments. Table 6 shows the results of the experiment without a smart watch and Table 7 shows the results with the smart watch. The "Total" column shows the average of all the numbers of "take back" for a subject. Subjects A and B have better average and standard deviation values, as shown in the "Total" column, with the use of the smart watch (Table 7) than without (Table 6). Subject $C$ shows a decrease in the standard deviation value by $0.1 \mathrm{~cm}$; however, the average value shows improvement. Therefore, the effectiveness of the smart watch can be confirmed.

The effectiveness of the smart watch can be also established from the best scores (gray columns) of all the subjects. Subject A showed improvement in both average and standard deviation values.

Table 5. Timing of heartbeat and throwing (\%)

\begin{tabular}{|l|l|l|l|l|}
\hline \multicolumn{2}{|c|}{ Number of "take back" } & Once & \multicolumn{1}{c|}{ Twice } & \multicolumn{1}{c|}{ Thrice } \\
\hline \multirow{4}{*}{ Subject 1 } & After & 44 & 22 & 33 \\
\cline { 2 - 6 } & Middle & 11 & 22 & 22 \\
\cline { 2 - 6 } & Before & 44 & 56 & 44 \\
\hline \multirow{5}{*}{ Subject 2 } & After & 78 & 22 & 33 \\
\cline { 2 - 6 } & Middle & 11 & 44 & 11 \\
\cline { 2 - 6 } & Before & 11 & 33 & 56 \\
\hline \multirow{5}{*}{ Subject 3 } & After & 56 & 67 & 22 \\
\cline { 2 - 6 } & Middle & 22 & 22 & 22 \\
\cline { 2 - 5 } & Before & 22 & 11 & 56 \\
\hline
\end{tabular}



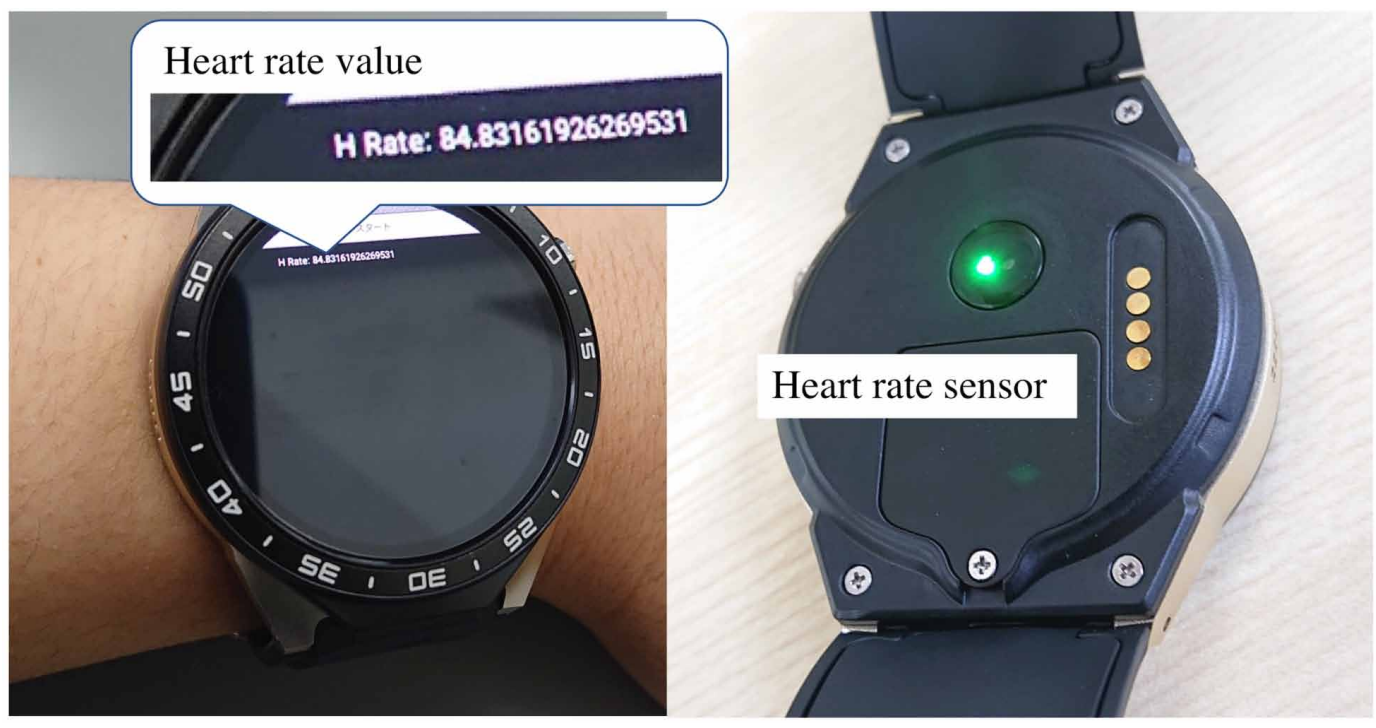

Table 6. Results without smart watch (unit: $\mathrm{cm}$ )

\begin{tabular}{|l|l|l|l|l|l|}
\hline \multicolumn{2}{|c|}{ Number of "take back" } & \multicolumn{1}{c|}{ Once } & \multicolumn{1}{c|}{ Twice } & \multicolumn{1}{c|}{ Thrice } & \multicolumn{1}{c|}{ Total } \\
\hline \multirow{3}{*}{ Subject A } & Average & 9.456 & 7.800 & 8.456 & 8.570 \\
\cline { 2 - 6 } & Standard dev. & 4.092 & 2.630 & 4.191 & 3.629 \\
\hline \multirow{3}{*}{ Subject B } & Average & 9.900 & 8.178 & 9.689 & 9.256 \\
\cline { 2 - 6 } & Standard dev. & 4.316 & 3.125 & 5.296 & 4.240 \\
\hline \multirow{3}{*}{ Subject C } & Average & 10.856 & 10.533 & 11.278 & 10.889 \\
\cline { 2 - 6 } & Standard dev. & 4.077 & 3.286 & 4.210 & 3.740 \\
\hline
\end{tabular}

The average value declined for Subject B by only $0.1 \mathrm{~cm}$; however, the standard deviation showed improvement. And the standard deviation declined for Subject $\mathrm{C}$ by $1.2 \mathrm{~cm}$; however, the average value was improved more than that. These indicated that Subjects B and C could achieve stable scores.

Table 7. Results with smartwatch (unit: $\mathrm{cm}$ )

\begin{tabular}{|l|l|l|l|l|l|}
\hline \multicolumn{2}{|c|}{ Number of “take back” } & \multicolumn{1}{c|}{ Once } & \multicolumn{1}{c|}{ Twice } & \multicolumn{1}{c|}{ Thrice } & \multicolumn{1}{c|}{ Total } \\
\hline \multirow{3}{*}{ Subject A } & Average & 4.944 & 7.856 & 8.178 & 6.993 \\
\cline { 2 - 6 } & Standard dev. & 2.440 & 2.879 & 3.446 & 3.199 \\
\hline \multirow{3}{*}{ Subject B } & Average & 8.278 & 8.989 & 9.844 & 9.037 \\
\cline { 2 - 6 } & Standard dev. & 1.666 & 3.990 & 4.306 & 3.447 \\
\hline \multirow{3}{*}{ Subject C } & Average & 10.733 & 9.233 & 9.100 & 9.689 \\
\cline { 2 - 6 } & Standard dev. & 2.120 & 4.669 & 4.464 & 3.845 \\
\hline
\end{tabular}


Table 8. Results with metronome (unit: $\mathrm{cm}$ )

\begin{tabular}{|l|l|l|l|l|l|}
\hline \multicolumn{2}{|c|}{ Number of "take back" } & \multicolumn{1}{c|}{ Once } & \multicolumn{1}{c|}{ Twice } & \multicolumn{1}{c|}{ Thrice } & \multicolumn{1}{c|}{ Total } \\
\hline \multirow{3}{*}{ Subject A } & Average & 6.590 & 8.129 & 7.038 & 7.300 \\
\cline { 2 - 6 } & Standard dev. & 3.186 & 4.092 & 3.836 & 3.810 \\
\hline \multirow{3}{*}{ Subject B } & Average & 7.095 & 6.338 & 7.210 & 6.900 \\
\cline { 2 - 6 } & Standard dev. & 4.068 & 3.466 & 4.017 & 3.911 \\
\hline \multirow{3}{*}{ Subject C } & Average & 10.248 & 9.086 & 9.895 & 9.700 \\
\cline { 2 - 6 } & Standard dev. & 5.037 & 5.202 & 3.838 & 4.795 \\
\hline
\end{tabular}

As evident from Tables 6 and 7, the number of "take back" to achieve the best score changed in the two experiments; without and with smart watch. This means that the PPR changed as the subjects had to synchronize their throws with the heartbeat sound. The PPR in which the throws were easy for the subjects was not selected; rather, the PPR in which it was easy for the subjects to synchronize the throw was selected.

The experiments described in the previous section showed that scores were improved by throwing darts immediately after a heartbeat sound. However, it can be considered that higher scores were achieved by throwing in a constant rhythm, which is not related to heartbeat. Therefore, an experiment was conducted using a metronome to verify the effectiveness of heartbeat. The metronome was set to 65 beats per minute (bpm), which is the general heart rate of males at rest. The experiment was conducted with the same subjects as in the previous experiment. However, because of the time gap between the two experiments (about six months), the experiment with the smart watch was re-conducted.

Table 8 shows the results of the experiment with a metronome and Table 9 shows the results of the experiment with heartbeat sounds. As each subject often played darts game during the time gap, scores became better than in the previous experiment. Compared with using a metronome, Subjects $\mathrm{A}$ and $\mathrm{C}$ obtained higher total scores and best scores using heartbeat sounds. Based on this, the effectiveness of throwing along with heartbeat rhythm, which is not simple, could be confirmed. As for Subject B, the average and standard deviation for both total score and best score decreased by several millimeters.

The time lags between throwing and sounds of metronome and heartbeat were checked in the video recordings. Table 10 shows the relationship between time lag and score. The scores have been calculated as the average for all the subjects in each interval of time lag. The maximum time lag was $0.15 \mathrm{~s}$, which indicated that all the subjects could throw darts immediately after hearing sounds. It can be observed that smaller time lag led to worse scores. It can be reasoned that subjects concentrated to synchronize with the sound rather than on throwing darts at the center.

Table 9. Results with heartbeat sound (unit: $\mathrm{cm}$ )

\begin{tabular}{|l|l|l|l|l|l|}
\hline \multicolumn{2}{|c|}{ Number of “take back” } & \multicolumn{1}{c|}{ Once } & \multicolumn{1}{c|}{ Twice } & \multicolumn{1}{c|}{ Thrice } & Total \\
\hline \multirow{3}{*}{ Subject A } & Average & 5.986 & 4.052 & 6.048 & 5.362 \\
\cline { 2 - 6 } & Standard dev. & 2.726 & 1.877 & 3.823 & 3.088 \\
\hline \multirow{3}{*}{ Subject B } & Average & 6.562 & 8.081 & 6.971 & 7.205 \\
\cline { 2 - 6 } & Standard dev. & 4.094 & 4.673 & 3.743 & 4.271 \\
\hline \multirow{3}{*}{ Subject C } & Average & 8.462 & 7.333 & 9.357 & 8.384 \\
\cline { 2 - 6 } & Standard dev. & 4.754 & 4.830 & 4.128 & 4.693 \\
\hline
\end{tabular}


Table 10. Relationships between time lag and score

\begin{tabular}{|l|l|l|}
\hline \multicolumn{1}{|c|}{ Time lag $(\mathbf{s})$} & \multicolumn{1}{c|}{ Metronome $(\mathbf{c m})$} & \multicolumn{1}{c|}{ Heart beat $(\mathbf{c m})$} \\
\hline $0 \sim 0.02$ & 7.947 & 7.063 \\
\hline$\sim 0.04$ & 8.250 & 7.425 \\
\hline$\sim 0.06$ & 8.422 & 7.334 \\
\hline$\sim 0.08$ & 7.556 & 6.958 \\
\hline$\sim 0.15$ & 7.042 & 6.489 \\
\hline
\end{tabular}

Table 11 summarizes average time lags of each subject. Subject B had considerably small time lag values for heartbeat, when compared with other subjects or metronome values. It can be interpreted that Subject B concentrated too much on synchronizing with the heartbeat sound. Therefore, the effectiveness of heartbeat could not be obtained, and the score of Subject B did not improve.

In the first experiment in this section, the best score for the number of "take back" or PPR changed during the throwing with heartbeat sound. It was observed that the number of "take back" that was easy to synchronize with the heartbeat rhythm was selected. However, the results of the second experiment with heartbeat sounds (Table 9) indicated the best scores (or PPRs) of Subjects $\mathrm{A}$ and $\mathrm{C}$ were under "twice take back." These corresponded to the results of the first experiment performed without a smart watch (Table 6). Subject B could not perform his original throwing, probably because he concentrated too much on synchronizing with the heartbeat. Subjects A and C got used to throwing at the timing of a heartbeat, and were able to perform their original throwing, even while synchronizing with the heartbeat sound. It is clearly understood that PPRs for Subjects $\mathrm{A}$ and $\mathrm{C}$ did not change.

\section{CONCLUSION}

In this paper, two types of cognitive support tool for PPRs in darts game were introduced. The support tool using a simple brain-wave sensor shows us the baseline concentration level of the subject, and indicates the concentration-stabilizing phenomenon on a tablet computer. The effectiveness of the tool was confirmed through experimental dart games. The another tool has been developed on a smart watch with a heart rate sensor. The smart watch indicated heartbeat as a "beep" sound to a user. The effectiveness of the system was verified and compared with a metronome in another experiment.

PPRs are very attractive and well-known techniques in sports. However, PPRs are unique to an individual (Cotterill et al., 2010), a general method for creating PPRs does not exist. Therefore, they are designed by trial and error through consultation and discussion among specialists and players (Marlow

Table 11. Time lag of each subjects (unit: $\mathbf{s}$ )

\begin{tabular}{|l|l|l|l|l|l|}
\hline \multicolumn{2}{|c|}{ Number of “take back” } & \multicolumn{1}{c|}{ Once } & \multicolumn{1}{c|}{ Twice } & \multicolumn{1}{c|}{ Thrice } & Avg. \\
\hline \multirow{3}{*}{ Subject A } & Metronome & 0.083 & 0.067 & 0.062 & 0.071 \\
\cline { 2 - 6 } & Heartbeat & 0.080 & 0.045 & 0.058 & 0.061 \\
\hline \multirow{3}{*}{ Subject B } & Metronem & 0.019 & 0.025 & 0.046 & 0.030 \\
\cline { 2 - 6 } & Heartbeat & 0.018 & 0.015 & 0.018 & 0.017 \\
\hline \multirow{2}{*}{ Subject C } & Metroneme & 0.040 & 0.044 & 0.079 & 0.054 \\
\cline { 2 - 6 } & Heartbeat & 0.068 & 0.052 & 0.064 & 0.061 \\
\hline
\end{tabular}


et al., 2011). However, the support tools allows us to objectively determine the type of behavioral sequences that are appropriate for PPRs by monitoring of brainwaves or heartbeat. Moreover, once a PPR is configured, we can train a specific PPR to stabilize concentration or to throw immediately after a heartbeat in the subject.

Although this study was focused on darts game, the results and the system can be applied to other sports such as golf, which is a competition in which a player can act based on their own timing. In future studies, the effectiveness of our tools will be verified in various sports over a long period of time.

\section{ACKNOWLEDGMENT}

This research is supported by JSPS KAKENHI Grant Number JP17K01709. I would like to thank Editage (www.editage.com) for English language editing. 


\section{REFERENCES}

Ardigò, L. P., Kuvacic, G., Iacono, A. D., Dascanio, G., \& Padulo, J. (2018). Effect of Heart rate on Basketball Three-Point Shot Accuracy. Frontiers in Physiology, 9(75), 1-6. doi:10.3389/fphys.2018.00075 PMID:29467676

Cotterill, S. T. (2010). Pre-performance routines in sport: Current understanding and future directions. International Review of Sport and Exercise Psychology, 3(2), 132-153. doi:10.1080/1750984X.2010.488269

Cotterill, S. T. (2011). Experiences of Developing Pre-performance Routines with Elite Cricket Players. Journal of Sport Psychology in Action, 2(2), 81-91. doi:10.1080/21520704.2011.584245

Cotterill, S. T., Sanders, R., \& Collins, D. (2010). Developing effective pre-performance routines in golf: Why don't we ask the golfer? Journal of Applied Sport Psychology, 22(1), 51-64. doi:10.1080/10413200903403216

Delliaux, S., Delaforge, A., Deharo, J., \& Chaumet, G. (2019). Mental Workload Alters Heart Rate Variability, Lowering Non-linear Dynamics. Frontiers in Physiology, 10(565), 1-14. doi:10.3389/fphys.2019.00565 PMID:31156454

Hiraishi, H. (2015). Designing a robot controller by using a simple brain-wave sensor and a machine learning technique. Journal of Artificial Life and Robotics, 20(3), 217-221. doi:10.1007/s10015-015-0224-y

Hiraishi, H. (2017). Qualitative Analysis of Concentration Level in Throwing Using Simple Brain-Wave Sensor. International Journal of Cognitive Informatics and Natural Intelligence, 11(3), 17-30. doi:10.4018/ IJCINI.2017070102

Hiraishi, H. (2018). Pre-performance routine training tool using simple brain-wave sensor. 2018 IEEE International Conference on Systems, Man, and Cybernetics, 982-985. doi:10.1109/SMC.2018.00175

Hiraishi, H. (2020). Heart rate analysis for pre-performance routine in darts game. The 19th International conference on Cognitive informatics \& Cognitive Computing, ICCI*CC'20, 34-38.

Kim, J., Lee, H. M., Kim, W. J., Park, H. J., Kim, S. W., Moon, D. H., Woo, M., \& Tennant, L. K. (2008). Neural correlates of pre-performance routines in expert and novice archers. Neuroscience Letters, 445(3), $236-241$. doi:10.1016/j.neulet.2008.09.018 PMID:18805460

Lonsdale, C., \& Tam, J. T. (2008). On the temporal and behavioural consistency of pre-performance routines: An intra-individual analysis of elite basketball players' free throw shooting accuracy. Journal of Sports Sciences, 26(3), 259-266. doi:10.1080/02640410701473962 PMID:17943592

Marlow, C., Bull, S. J., Heath, B., \& Shambrook, C. J. (1998). The Use of a Single Case Design to Investigate the Effect of a Pre-performance Routine on the Water Polo Penalty Shot. Journal of Science and Medicine in Sport, 1(3), 143-155. doi:10.1016/S1440-2440(98)80010-8 PMID:9783516

Mesagno, C., \& Mullane-Grant, T. (2010). A Comparison of Different Pre-Performance Routines as Possible Choking Interventions. Journal of Applied Sport Psychology, 22(3), 343-360. doi:10.1080/10413200.2010.4 91780

Milton, J., Solodkin, A., Hluštík, P., \& Small, S. L. (2007). The mind of expert motor performance is cool and focused. NeuroImage, 35(2), 804-813. doi:10.1016/j.neuroimage.2007.01.003 PMID:17317223

Pomeranz, B., Macaulay, R. J. B., Caudill, M. A., Kutz, I., Adam, D., Gordon, D., Kilborn, K. M., Barger, A. C., Shannon, D. C., Cohen, R. J., \& Benson, H. (1985). Assessment of autonomic function in humans by heart rate spectral analysis. The American Journal of Physiology, 248, 151-153. PMID:3970172

Velentzas, K., Heinen, T., \& Schack, T. (2011). Routine Integration Strategies and their Effects on Volleyball Serve Performance and Players' Movement Mental Representation. Journal of Applied Sport Psychology, 23(2), 209-222. doi:10.1080/10413200.2010.546826 
Hironori Hiraishi received a B.S. degree in 1993, his M.S. degree in 1996, and a Ph.D. in 1999 in information technology from Tokyo University of Science. He was a research associate of Information Media Center in Tokyo University of Science from 2000 to 2005, chief technological officer of WisdomTex, Inc. from 2001 to 2009, an associate professor of department of electrical and computer engineering in National Institute of Technology, Akita College from 2010 to 2016, and an associate professor of faculty of engineering in Ashikaga Institute of Technology from 2017 to 2019. He is a professor of faculty of engineering in Ashikaga University from 2020. He received the winning award on the Innovative Application conference (IAAI2003), and the best paper award twice on the Cognitive Informatics and Cognitive Computing conference (ICCI ${ }^{*} C C 2011$ and ICCI ${ }^{*} C$ C2017). His recent research interests have focused on the applications integrating with human cognitive aspects and Al technologies. 